\title{
PRÁTICAS DE ESCRITA E DE LEITURA NO CONVENTO DE SANTA CLARA DO DESTERRO DA BAHIA (SÉCULOS XVII E XVIII) ${ }^{1}$
}

\author{
WRITING AND READING PRACTICES AT THE SAINT CLARE OF RELEGATION \\ NUNNERY OF BAHIA(XVII AND XVIII CENTURY)
}

\author{
ESCRITAS CONVENTUAIS FEMININAS NA AMÉRICA PORTUGUESA
}

\section{FEMALE CONVENTUAL WRITINGS IN PORTUGUESE AMERICA}

\author{
LAGE, Ana Cristina Pereira ${ }^{2}$
}

\begin{abstract}
Resumo
Este artigo busca dialogar com o conceito de cultura escrita para compreender as leituras possíveis e as escritas realizadas pelas religiosas que habitavam o Convento de Santa Clara do Desterro da Bahia, primeira instituição do gênero fundada na América Portuguesa, no ano de 1677. No interior de conventos, destacavam-se as escritas e as leituras das autobiografias ou biografias de companheiras de claustro, de vida dos santos ou textos morais edificantes (exemplares). Pretende-se então analisar algumas obras exemplares que foram produzidas no referido convento.
\end{abstract}

Palavras- chave: Cultura escrita; América Portuguesa; Educação Feminina; Claustros

\begin{abstract}
This article searches correlate the written culture concept in order to comprehend some possible readings and the scripts by the religious women who lived at the Saint Claire's Nunnery of Bahia, first institution of its kind founded at the Portuguese America, from the year of 1677. At the interior of the Nunneries stood out even some autobiographical and biographical of cloister companions, of live of saints or moral texts (copies). It is then intended to analyze some exemplary lives that were produced in that convent.
\end{abstract}

Keyword: Written culture; Portuguese America; Women's Education; Cloisters

\footnotetext{
${ }^{1}$ Este artigo apresenta resultados parciais da pesquisa em desenvolvimento Práticas de leitura e escrita das irmãs clarissas em conventos portugueses e brasileiros no século XVIII. Trata-se de uma pesquisa de pósdoutorado, com a supervisão da professora Dra. Terezinha Oliveira (UEM) e financiamento CAPES.

2 Professora do curso de Licenciatura em História e do Mestrado Profissional Interdisciplinar em Ciências Humanas da Universidade Federal dos Vales do Jequitinhonha e Mucuri - Campus Diamantina. Doutora em Educação (UFMG). Pós doutoranda em Educação (UEM). Integrante dos grupos de Pesquisa Cultura e Educação na América Portuguesa (GCEAP) e Transformações Sociais e Educação na Antiguidade e Medievalidade. Bolsista CAPES.
} 


\section{Introdução}

Este trabalho dialoga com o campo teórico da cultura escrita e o campo temático da história da educação confessional feminina para compreender as possíveis leituras e escritas realizadas pelas religiosas que habitavam o Convento de Santa Clara do Desterro da Bahia nos séculos XVII e XVIII, a primeira instituição feminina do gênero fundada na América Portuguesa. É importante salientar a existência de uma historiografia que trata o Convento de Santa Clara do Desterro da Bahia em suas especificidades. Ana Amélia Vieira Nascimento (1994) trata das relações políticas e econômicas que estavam imbrincadas no surgimento e no fortalecimento da referida instituição. Emanuel Araújo (1997) discute o cotidiano das irmãs e retrata os desvios com relação à vida religiosa existentes no convento. O presente artigo dialoga com a historiografia existente, porém busca apresentar um outro olhar para a compreensão histórica da instituição a partir da análise das suas práticas de leitura e de escrita.

O Convento de Santa Clara do Desterro da Bahia é aqui analisado enquanto uma instituição educativa, uma vez que foi criado para satisfazer determinadas necessidades humanas e esteve em constante construção e transformação ao longo do período analisado. Uma instituição constitui-se como um sistema de práticas, com agentes e instrumentos que atingem as finalidades esperadas para o ordenamento da educação de um determinado grupo social (MAGALHÃES, 2004). Neste artigo, as práticas são consideradas enquanto "maneiras de fazer" cotidianas dos sujeitos históricos e que são relacionadas social e culturalmente, na construção de seus espaços, suas posições e suas identidades (CHARTIER, 1990).

As práticas situam a análise da cultura escrita no plano dos usos dados, das competências efetivas do escrever e do ler, e dos modos de colocá-lo em uso. Por um lado, levam às evidencias materiais de cada exercício de escrita e de leitura; e por outro, assinalam as condições nas quais se fazem possíveis. (GOMEZ, 2003). Por sua vez, a leitura é uma prática "encarnada em gestos, espaços, hábitos". Aqueles que têm a capacidade de ler um texto não os lêem da mesma forma e com as mesmas habilidades. Além disso, existem comunidades de leitores que apresentam determinados "modos de ler, instrumentos e processos de interpretação" (CHARTIER, 1997, p.15) É possível inferir que existia uma prática de leitura desigual entre as mulheres que habitavam os conventos femininos nos séculos XVII e XVIII. Por outro lado, é necessário considerar que leitura e escrita são práticas 
adquiridas pelo homem de formas distintas, uma vez que nem todos aqueles que aprendem a ler possuem o domínio da escrita.

Para Antônio Castilho Gomes (2003), o hábito da escrita divide-se em três momentos. O primeiro seria referente à aquisição do escrito, que depende da individualidade dos sujeitos no aprendizado, mas também categoriza os grupos sociais nas diversas temporalidades históricas. O segundo momento seria aquele da produção do escrito que depende das circunstancias que intervêm no momento de criar ou fabricar um produto de cultura escrita. $\mathrm{O}$ último momento refere-se à recepção, que conecta as práticas da escrita com as práticas de leitura, pois interliga autor e leitor. Diante do exposto, algumas indagações são pertinentes para compreender as práticas de escrita e de leitura entre as irmãs clarissas que habitavam o primeiro convento brasileiro, uma vez é necessário compreender quem, o que, quando, onde, por quais motivos, de que modo lêem e/ ou escrevem. Mas antes de buscar responder às indagações aqui apresentadas, torna-se necessário compreender as especificidades da fundação da instituição que será aqui analisada.

\section{O Convento de Santa Clara do Desterro da Bahia}

Desde 1644 ocorreram diversas solicitações para a abertura de um convento feminino na América Portuguesa, mas foi somente em 1665 que a Câmara de Salvador conseguiu a autorização do Rei D. Afonso VI (JABOATÃO, 1858). A análise da documentação demonstra que as súplicas para a fundação de uma instituição de reclusão feminina na América Portuguesa eram justificadas pelo longo e custoso caminho que as moças da colônia tinham que percorrer para ingressarem nos conventos portugueses. Verifica-se que o ingresso em um convento fazia parte não só dos anseios femininos, como das próprias famílias, uma vez que ter uma filha enclausurada poderia significar um ganho religioso nas relações daquele grupo com o mundo "celeste", uma vez que as futuras religiosas eram consideradas intermediárias junto a Deus, por meio de suas orações ou das suas supostas relações maritais com Jesus Cristo. A intencionalidade na abertura de um convento feminino na América Portuguesa também apresentava questões políticas, econômicas e sociais de pano de fundo, uma vez que, especialmente os pais pertencentes à elite soteropolitana, não desejavam casar as suas filhas com homens que consideravam como pertencentes às categorias sociais proclamadas como "inferiores" e, mais ainda, percebiam que os dotes encaminhados aos conventos eram menores do que aqueles que eram fornecidos aos futuros maridos. Muitas vezes consideravam que ingressar uma filha em um convento tornava-se mais barato e mais 
prestigioso do que casá-la. Assim, para um pai que possuía diversas filhas, o controle dos casamentos era primordial para os seus gastos financeiros e o encaminhamento de parte de suas descendentes ou de todas para um convento tornava-se uma questão de manutenção de sua fortuna e do status familiar e local.

A provisão real de 1665 para a fundação da referida instituição deixava claro que, após a doação da "ermida do Desterro" pela Coroa, todos os gastos para a construção viriam por meio de "esmolas" da população local (JABOATÃO, 1858, p.629). As concessões de esmolas eram carregadas de intencionalidades, uma vez que estavam condicionadas às negociações de futuros lugares para as filhas dos benfeitores na instituição. Segundo Ana Amélia Vieira Nascimento (1994, p.72), os documentos de fundação do Convento do Desterro demonstram uma preocupação tanto do poder laico quanto do poder religioso de garantir ainda o sustento da instituição após a construção do prédio, uma vez que o "material é realçado em detrimento do espiritual". O sustento da instituição viria especialmente por meio da continuidade de esmolas e dos dotes das educandas (meninas com menos de 12 anos de idade), noviças e freiras. Dessa forma, o enclausuramento de mulheres da elite local garantiria a construção e a manutenção do referido convento.

Após 12 anos do início da construção inacabada do prédio, no ano de 1677 chegaram à cidade de Salvador quatro irmãs clarissas e duas servas portuguesas, oriundas do Convento de Santa Clara de Évora. A intenção era implantar os princípios das clarissas lusitanas no território da América Portuguesa. É importante salientar que, no século XIII, momento no qual Santa Clara inaugurou a sua comunidade religiosa, já foram fundados quatro conventos de clarissas em solo português: Lamego, Entre Rios, Coimbra e Lisboa. Até 1834, foram instituídos oitenta e quatro conventos de clarissas em Portugal e nas ilhas adjacentes (FARIA, 1994). O florescimento do culto à Santa Clara ainda no período medieval acarretou a fundação de conventos em Portugal que já eram caracterizados como lugares para o recolhimento de mulheres da nobreza. Devido às peculiaridades da religiosidade lusitana para que os fiéis alcançassem a "salvação", muitas das instituições clarianas foram financiadas por mulheres ou homens abastados com este propósito, uma vez que o convento seria um espaço para o futuro enterramento e ainda garantiria a oração das religiosas pela salvação da alma do benfeitor. Assim, a abertura das casas conventuais e monásticas em Portugal tinha finalidades de estratégias pessoais. 
A necessidade de acertar contas com o Além, procurando um medianeiro, e intercessor, com o Céu, que seria o Mosteiro, embora constituísse um desejo pio de manifesta devoção, não deixava de ser uma manifestação egoísta, que pressupunha uma vontade de iniciar, em vida, uma troca de favores com Deus. (SARAMAGO, 1994)

Muitos conventos foram instituídos por membros da realeza, como foi ocorreu no Real Convento da Conceição de Beja, inaugurado em 1459 pelo infante D. Fernando e sua esposa D. Beatriz, pais do futuro rei D. Manuel I (SARAMAGO, 1994). Outros conventos de clarissas foram instituídos pelo poder religioso, como aconteceu com o Convento de Santa Clara de Évora, que em 1458 foi financiado pelo bispo D. Vasco Perdigão (VASCONCELOS E SOUSA, 2005). É importante salientar que os fundadores destas instituições confessionais femininas ainda direcionavam e controlavam a eleição das religiosas para os cargos mais importantes, além da entrada das educandas e noviças, desconsiderando as regras e constituições das clarissas.

Os conventos das clarissas em Portugal e na América Portuguesa constituíram-se em espaços de poderes por receberem mulheres das elites, que estavam correlacionadas com as esferas políticas e religiosas locais. Segundo Maria Filomena Andrade (2011, p.24) "precisamos, assim, de ter sempre presente que a realidade monástica feminina não é apenas o fruto de uma imposição social e muito menos religiosa, mas constitui-se ela própria como uma fonte de dinamismo e poder". O ingresso de uma mulher em um convento de clarissas no período moderno, especialmente em Portugal e na América Portuguesa significava a manutenção deste dinamismo e das relações de poder. Ao analisar a literatura conventual feminina portuguesa nos séculos XVII e XVIII, Ligia Bellini (2010) aponta que até as obras produzidas no interior dos claustros faziam parte de uma rede de negociações entre os conventos e a Corte. Esta relação se dava nas autorizações para a publicação das obras, do ingresso e da profissão de freiras e, finalmente, na definição e controle dos cargos de administração de um determinado convento.

No período que compreende esta pesquisa, o Convento de Santa Clara do Desterro da Bahia foi habitado principalmente por mulheres que pertenciam à elite baiana, que viviam em um ambiente de faustos, luxos e riquezas e que demonstravam uma liberdade única por viverem em certa medida distantes dos controles da sociedade patriarcal. A instituição era procurada por mulheres que realmente desejavam levar uma vida contemplativa e que perseguiam uma determinada perfeição religiosa, mas também haviam aquelas mulheres que habitavam o espaço para ter uma certa liberdade em suas ações com relação ao que era 
desejado para o seu estado de religiosa. A diversidade das mulheres que lá habitavam propiciava os distanciamentos no convento: solteiras, virgens, "decaídas", órfãs, viúvas, separadas de seus maridos, etc. Por outro lado, havia uma divisão social no interior do claustro, uma vez que a entrada e a detenção do poder institucional dependeria dos valores dos dotes e das contribuições familiares que eram desprendidos (NASCIMENTO, 1994). Observa-se que o cotidiano dos grupos sociais que habitavam o Convento do Desterro na Bahia e das demais clarissas em Portugal distanciavam-se muito dos princípios propostos pela fundadora, que pregava o voto de pobreza enquanto ponto fulcral para a inserção feminina no grupo religioso. Verifica-se então a necessidade de compreender o distanciamento das religiosas seiscentistas e setecentistas com relação às seguidoras dos princípios de Clara de Assis no período medieval.

\section{Particularidades e diferenças das clarissas}

Clara de Assis (1194-1253) fez parte de um pequeno grupo de mulheres do período medieval que, dentro dos muros conventuais, ao professar votos de pobreza e silêncio, demonstravam os seus pensamentos por meio da escrita. Da sua obra, poucos escritos chegaram até a atualidade: a primeira Regra das clarissas (1247), considerada como a primeira ordenação elaborada por uma mulher no mundo medieval; um testamento, uma benção e cinco cartas (PEDROSO, 2004, p.15). Como fundadora de um novo grupo de religiosas, Santa Clara foi responsável por inaugurar uma tradição letrada entre as suas seguidoras. Assim, para as clarissas, desde o período medieval e seguindo o modelo da fundadora, verifica-se o desenvolvimento de práticas de leitura e de escrita em seus cotidianos claustrais. A Primeira Regra de Santa Clara (1247), aprovada pelo papa Inocêncio IV, já previa o aprendizado da leitura, uma vez que em seu capítulo III, direcionava a prática do Ofício Divino, o dever de rezar dado aos religiosos conventuais e ainda apontava para a observância da leitura de determinadas orações em horários específicos. Porém, a Primeira Regra já designava que, aquelas que não liam, deveriam rezar determinadas orações.

As irmãs que sabem ler rezem o Ofício Divino conforme o costume dos Frades Menores, pelo que poderão ter Breviários, lendo sem canto. E aquelas que, por causa razoável, alguma vez não puderem dizer suas Horas lendo, possam dizer os Pai- nossos como as outras irmãs. E as irmãs que não sabem ler digam vinte e quatro vezes o Pai- nossos pelas Matinas; cinco pelas Laudes; por Prima, Terça, Sexta e Noa, por cada uma dessas Horas, sete; pelas Vésperas doze e pelas Completas sete. (PEDROSO, 2004, p.24) 
O documento apresentado por Clara de Assis demonstra que este compreende uma interpretação e ressignificação de outros documentos que foram impostos para a sua comunidade ao longo de sua existência. A instituição da Primeira Regra prova que "ela conhecia muito bem e soube usar com precisão tanto a regra de São Francisco como a de São Bento" e, além disso, complementou os seus escritos com o seu "conhecimento da Bíblia, dos autores sacros do seu tempo e de uma experiência toda original” (PEDROSO, 2004, p.18).

Uma Segunda Regra para as irmãs clarissas foi proposta pelo papa Urbano IV (1263), poucos anos após a morte da religiosa, com a intenção de proporcionar um melhor direcionamento para a ordem religiosa e diminuir a rigidez da proposta anterior. É possível detectar que a Segunda Regra aproxima-se daquela proposta por Clara, especialmente com relação às práticas de leitura das irmãs, uma vez que também determinava que as religiosas deveriam saber ler para celebrar o Ofício Divino. (URBANO IV, Regra das Freyras de Santa Clara. Apud. FREI JOSEPH DE JESUS MARIA, 1718)

Pesquisadores apontam que a principal diferença entre as duas regras estaria no alcance do voto de pobreza e na união jurídica com a Ordem de S. Francisco que, na Regra proposta pelo papa Urbano IV foi modificada, pois passou para o Governo de um Cardeal Protetor. Além disso, a proposta urbanista impôs a obrigatoriedade do dote para a inclusão das mulheres na clausura e previu propriedades e rendas para os conventos. Com relação ao Ofício Divino, propiciou a prática do canto nos momentos de orações (PEREIRA, 2011). Embora distanciados do pensamento inicial proposto por Santa Clara na Primeira Regra, verifica-se que, nos séculos XVII e XVIII, a maioria dos conventos de irmãs clarissas em Portugal e o Convento de Santa Clara do Desterro na Bahia (Mercê do Rei D. Afonso VI para a criação do Mosteiro de Santa Clara do Desterro, 1665. Apud JABOATÃO, 1858. p. 627629), seguiram a regra proposta por Urbano IV, mais propícia aos interesses das mulheres que habitaram aqueles espaços, também chamadas de Urbanistas. É importante observar que as primeiras mulheres que tinham relação direta com a fundadora também pertenciam a uma determinada elite medieval, mas a eleição da pobreza e o abandono dos bens pessoais e familiares ao optarem pela vida religiosa, acarretava um modo de vida diferenciado daquele que foi proposto para aquelas mulheres recolhidas nos conventos urbanistas. A presença do dote para o ingresso e a posse de bens da comunidade eram primordiais para o funcionamento deste último grupo. No período moderno, observa-se a existência das clarissas que seguiam a Primeira Regra (Descalças); aquelas que seguiam a Segunda Regra (Urbanistas ou Urbanas), 
que perfaziam a grande maioria do grupo; e aquelas que seguia uma Terceira Regra (Terceiras da Penitência), criada pelo papa Leão X em 1517, que serviria aos franciscanos e às clarissas, dentro do movimento da Reforma Católica e que buscavam uma maior observância dos princípios de São Francisco. A análise das regras propicia a compreensão das especificidades e das continuidades das clarissas do período moderno com relação às mulheres que conviveram com Clara de Assis.

\section{Práticas de escrita e de leitura das clarissas}

A obra Espelho de perfeytas religiosas, publicada em Portugal em 1718 pelo franciscano José de Jesus Maria foi produzida para propiciar às religiosas urbanistas a compreensão e interpretação da $2^{\mathrm{a}}$ Regra. $\mathrm{O}$ autor aponta como deveria ser o cotidiano das clarissas na busca da sua perfeição religiosa. O espelho seria responsável por refletir o modelo a ser seguido (BELO, 1993). Para o franciscano, a busca da perfeição só aconteceria pelo aprendizado da leitura em latim. Aponta ainda que existiam três tipos de leitoras: aquelas que liam e não compreendiam o latim; aquelas que liam e compreendiam; e ainda aquelas que liam, entendiam e "falavam com Deus". Este último tipo seria considerado como o ideal para alcançar a perfeição religiosa. (FREI JOSEPH DE JESUS MARIA, 1718)

Por meio da análise da obra acima citada, ainda é possível detectar que, dentro de um mosteiro de clarissas, as religiosas dividiam-se em duas categorias: irmãs de Coro, por saberem ler; e irmãs Conversas, que não sabiam ler. A distinção do conhecimento da leitura aparecia até nos hábitos trajados pelas irmãs, uma vez que aquelas do Coro usavam um véu preto e as Conversas um véu branco. Aquelas que não possuíam a leitura, as irmãs Conversas, também participavam de uma certa cultura escrita, o que podemos categorizar como letramento religioso ${ }^{3}$, uma vez que deveriam decorar determinadas orações e seguir todas as orientações da regra, além de escutar as leituras em voz alta das demais religiosas. Neste sentido, ler significava entrar em contato com os textos impressos ou manuscritos, sendo que

\footnotetext{
${ }^{3} \mathrm{O}$ letramento religioso deve ser compreendido por meio dos usos sociais da leitura e da escrita para a formação de uma cultura para uma determinada instituição. Torna-se um modelo que pretende definir quem é, e quem não é letrado. No caso das irmãs clarissas, considera-se que, quanto maior o letramento voltado para o conhecimento religioso, maior seria a aproximação com Deus. É anda necessário levar em consideração as diferenças entre os grupos sociais quanto ao material escrito disponível, quanto aos valores atribuídos à escrita e quanto aos usos que são feitos da escrita e da leitura. O letramento religioso de mulheres reclusas compreende uma indicação de determinados livros e comportamentos necessários para o fortalecimento das práticas devocionais. (LAGE, 2014)
} 
a escrita pressupunha a decifração e a reprodução da letra escrita e, portanto, as mulheres enclausuradas desenvolviam essas habilidades de forma diferenciada. (LAGE, 2014)

Além da Regra, as irmãs clarissas deveriam seguir as Constituições Gerais propostas pelos Franciscanos no século XVII. Este documento apresenta uma preocupação com o tipo de leitura realizada nos Conventos clarianos, como indica a publicação portuguesa de 1693:

Para crescer no Santo exercício da Oração é de grande importância ler livros santos, e devotos; e assim exortamos a todas as Religiosas os leiam na Comunidade, e em particular; e proibimos com todo o rigor, se não consintam nos Conventos livros de comedias, nem outros quaisquer, que expressa, ou tacitamente contenham vaidades, ou carnalidades, ou coisas de pessoas mundanas: e a Abadessa, que os consentir, seja castigada pelo Provincial; e a Religiosa, em cujo poder se achar, dirá a culpa no refeitório, levando o livro ao pescoço; aonde será queimado diante da Comunidade. (CONSTITUIÇÕES GERAES, 1693, p. 84).

As penalidades causadas pelas leituras dos livros interditados seriam imputadas não somente para a leitora, mas também para a sua Abadessa ${ }^{4}$. Além disso, havia um castigo moral para a leitora diante da sua comunidade. Por outro lado, a análise das Constituições propicia a compreensão de que a leitura de obras "autorizadas" faria parte do cotidiano das irmãs clarissas que detinham este domínio e eram realizadas em comunidade ou individualmente. Em comunidade, a leitura aconteceria nos momentos de celebração do Ofício Divino, quando as freiras fariam suas refeições ou quando trabalhariam manualmente, pois sempre haveria uma encarregada em ler algo edificante para não deixar o "pensamento livre". Os momentos de leituras individuais eram necessários e as Constituições determinavam que cada freira teria uma hora de oração mental por dia. "(...) E antes da Oração se leia um livro espiritual, que administre matéria pera a Oração, e contemplação" (CONSTITUIÇÕES GERAES, 1693, p. 84). Tais livros poderiam pertencer à comunidade ou ainda serem privados e guardados nas celas de cada religiosa, propiciando então uma posse individual de livros permitidos.

E quais seriam as obras permitidas para a leitura no interior dos conventos? Segundo Leila Algranti (2004), as obras edificantes para compor uma biblioteca de um convento no século XVIII poderiam ser classificadas como pertencentes aos gêneros de teologia moral,

\footnotetext{
${ }^{4}$ Caberia à Abadessa o controle e responder por todas as atividades do Convento que estivesse sob a sua administração, inclusive sobre o controle das leituras, entrada e saída de cartas da instituição. o mandato de uma Abadessa durava três anos e a sua reeleição só poderia acontecer após três anos do seu último mandato. (CONSTITUIÇÕES GERAES, 1693)
} 
livros de espiritualidade, livros de horas e vidas de santos, breviários, missais e vidas exemplares (ALGRANTI, 2004). Estes últimos devem ser considerados enquanto documentos importantíssimos para a compreensão do desenvolvimento e fortalecimento das instituições religiosas femininas, especialmente quando são analisadas as obras escritas por homens sobre a vida exemplar de determinadas religiosas, ou ainda aqueles escritos pelas mulheres recolhidas nestes espaços. É necessário ainda pensar que "as leituras das religiosas dependiam de fatores que vão desde as existências de determinados livros na casa até à possibilidade que pode ser oportunidade - de aquisição dos textos, passando pelo conselho do diretor ou pela obediência à mestra das noviças" (CARVALHO, 1997).

Além de pensar nas práticas de leitura, é necessário também dialogar com as práticas da escrita dessas mulheres. Segundo Lígia Bellini (2006/2007), a existência de capacitações desiguais ao saber letrado no interior dos conventos femininos pode também ser estendida à escrita. No interior de conventos, destacavam-se três tipos de escrita: uma doméstica ou institucional, que leva em consideração a administração da casa; uma de foro privado, como as correspondências; e ainda as autobiografias ou biografias de companheiras de claustro, de vida dos santos ou textos morais edificantes, considerados como exemplares. Este último tipo poderia ser doméstico e privado, mas em alguns casos poderia circular para outras casas religiosas femininas. Algumas vezes os manuscritos tornavam-se impressos e ganhavam popularidade entre outras religiosas. Os livros tinham um caráter devocional, mas também propunham uma formação moral, além de contribuir para o desenvolvimento de habilidades de leitura. Este gênero de escrita era específico dos Conventos, uma vez que uma escrita administrativa e de cartas era comum para outras instituições. O auge dessa prática de escrita em Portugal situa-se no século XVII. Porém, existem raras obras escritas na América Portuguesa (ALGRANTI, 2004).

As vidas exemplares eram obras escritas, em geral, por uma freira sobre si mesma (autobiografia), ou por outra(s) freira(s) que conviveram com uma religiosa de vida considerada como exemplar ou por um padre confessor (biografias). As autobiografias tornavam-se exercícios espirituais, atitudes de recolhimento, exames de consciência e afirmação do “eu”. Já as biografias relacionavam-se com a preservação da memória de mulheres que eram dignas de rememoração a partir de suas atitudes consideradas exemplares, que poderiam espelhar um determinado modo de vida para as demais religiosas. Uma obra exemplar poderia ser manuscrita e circular no interior do próprio convento, ou ser impressa e circular em outras instituições conventuais e também para o público em geral. Geralmente o 
ato da escrita, quer seja autobiográfica, ou biográfica, envolvia o direcionamento e ordenação dos confessores, aqueles homens que tinham contato direto com aquelas mulheres que tinham as suas vidas relatadas nestas obras. Era uma escrita imposta, obrigatória e exigida pelos confessores (BELO, 1993).

A escrita das vidas exemplares se aproxima do gênero hagiográfico, porém não deve ser confundida com aqueles textos produzidos no período medieval e que retratavam a vida de santos. "Das hagiografias medievais diferenciam-se, no entanto, não só pelo estilo, como por uma relação diferente com a divindade: mais próxima e menos temida, este é o objeto de um amor devocional por parte de um sujeito activo e consciente da sua individualidade." (BELO, 1993, p.35) O gênero que passava a predominar no período Moderno dentro dos muros conventuais era uma biografia ou autobiografia devota, a qual se limitava a sugerir a promoção de uma devoção, e omitia no texto aqueles elementos que concorreriam para a divulgação explicita de um culto e proposta de santificação, propiciando então a escrita de um caminho exemplar para outras religiosas. Neste ponto, torna-se importante compreender as especificidades das práticas de leitura e escrita no Convento de Nossa Senhora do Desterro da Bahia por meio da análise das obras exemplares.

\section{Práticas de escrita e de leitura no Convento do Desterro}

É possível ressaltar que o Convento do Desterro valorizava o ensino da leitura ou a entrada de mulheres que já dominavam este conhecimento, uma vez que o número de mulheres que almejavam portar o véu preto era constante, fato que tinha relação com aquelas pertencentes à elite da América Portuguesa. Compreender as tensões sobre o uso do véu preto na instituição também é relacionar este hábito com o domínio da leitura, uma que estas recolhidas tinham a capacidade de participar do Ofício Divino. O documento papal de autorização da instituição e datado de 1669, já aponta pistas para o controle sobre a quantidade de Irmãs que poderiam ter o conhecimento da leitura do breviário em latim:

(...) um mosteiro para cinquenta Freiras com Abadessa, ou Prioresa trienal, as quais guardem a segunda Regra de São Francisco, chamadas Urbanas, $e$ tragam véu negro. (...) -E que possam ser admitidas no mesmo Mosteiro tantas Freiras conversas, quantas pedir a razão, e parecer conveniente. (CLEMENTE IX, apud. JABOATÃO, 1858, p. 634) 
É possível perceber a necessidade do papa de delimitar o número de mulheres que poderia portar o véu negro e, consequentemente, celebrar o Ofício Divino, como uma espécie de controle sobre o domínio da leitura. $\mathrm{O}$ documento não demonstra uma preocupação com o número de irmãs de véu branco, as conversas, uma vez que este número seria vinculado às necessidades do Convento. Ressalta-se que havia uma hierarquização das clarissas, o que propiciava uma categorização no interior do claustro entre as Irmãs de Coro e as Conversas.

Os embates acerca da ampliação do número de Irmãs de Coro no Convento do Desterro permearam os requerimentos encaminhados aos reis portugueses por meio do Conselho Ultramarino a partir do momento da fundação da instituição. Tais requerimentos eram feitos tanto pelos pais e moças que desejavam ingressar na instituição ${ }^{5}$, quanto pelas Abadessas que indicavam educandas que já estavam na instituição e desejavam passar para o noviciado, ou ainda aquelas que já estavam no noviciado e desejavam entrar no Estado de Religiosa e, por conta da delimitação do número de lugares de véu preto no Convento do Desterro, requisitavam um aumento "supranumerário"6. Assim, é possível conhecer um pouco dos anseios e das práticas de escrita feminina que acabaram por criar vários lugares "supranumerários" de véu preto no referido Convento, uma vez que as mulheres que habitavam o Desterro tinham relações familiares de alianças de força política junto ao Reino e a negativa das suas requisições ocasionava conflitos políticos com a Coroa.

As pressões constantes da elite local para a entrada de suas filhas na instituição aconteciam em decorrência do status de ter uma filha religiosa de véu preto, ou então pela orfandade ou pelos dotes mais baixos daqueles dispendidos com as alianças matrimoniais e que poderiam ser menores quando eram encaminhados para o ingresso na vida religiosa. A aceitação de diversas religiosas "supranumerárias" e acarretou a suspensão da admissão de novas noviças em $1764^{7}$ e possibilitou uma visita de fiscalização e a escrita de uma Carta

\footnotetext{
${ }^{5}$ REQUERIMENTO de Francisca Maria ao rei [D. João V] solicitando concessão do lugar supranumerário do Convento de Santa Clara do Desterro da cidade da Bahia. 8 de fevereiro de 1747. Arquivo Histórico Ultramarino Bahia-Avulsos. Cx. 88. Doc. 7192

${ }^{6}$ REPRESENTAÇÃO da Abadessa do Convento de Santa Clara do Desterro, da Bahia, Sor Ana do Sacramento, e mais Religiosas à rainha [D. Maria I], solicitando a permissão de admissão de um maior número de religiosas no Convento, atendendo à vocação de muitas donzelas da mesma capitania. Bahia, 29 de outubro de 1779. Arquivo Histórico Ultramarino. Bahia-Avulsos. Cx. 178. Doc. 13318.

${ }^{7}$ CARTA do Arcebispo eleito D. Fr. Manuel de Santa Ignez para Francisco X. de Mendonça Furtado, na qual se refere à ordem regia que mandará suspender a admissão de noviças nos conventos das religiosas da Bahia, a respeito dos quais lhe dá diversas informações. Bahia, 30 de junho de 1764. Arquivo Histórico Ultramarino. Bahia- Eduardo de Castro e Almeida. Caixa 35. Doc. 6554- 6555.
} 
Pastoral do Frei Manuel de Santa Inês, arcebispo da Bahia. O Arcebispo detectou que havia 75 religiosas de véu preto que habitavam o local, número superior ao proposto no momento da fundação, e a maioria das recolhidas não seguia os preceitos propostos na Segunda Regra ou nas Constituições das clarissas, uma vez que não tinham vida comum, pois não se encontravam nem nos momentos de refeição, já que as suas servas faziam as suas comidas em suas luxuosas celas. Além disso, poucas compareciam nos momentos de Ofício Divino:

É notória a grande falta que há sempre de Religiosas para a reza do coro, e sendo o oficio cantado só corre por conta das Músicas esta obrigação, e devendo todas louvarem a Deus, e entoarem os seus louvores, cantando a canto de órgão, como se faz nas comunidades, recusam aprenderem o dito canto para se eximirem da obrigação de cantarem (...);

As hebdomadárias, cantoras e mais oficiais do coro costumam convidar quatro ou seis Religiosas para que estas supram por elas, ainda que estejam presentes no Coro: o que causa grande turbação na paz; por que além de serem muitas as isentas, algumas das outras, nem bem ler sabem. ${ }^{8}$

É importante salientar que este documento representa uma visão masculina de um religioso que pretendia reformar a instituição. Por outro lado, aponta pistas para a questão da capacidade de leitura dessas religiosas, ou ainda, demonstra a necessidade de refletir sobre a heterogeneidade do grupo feminino que habitava o Desterro, uma vez que naquele ambiente existiam pessoas que realmente desejavam levar uma vida contemplativa e que perseguiam a perfeição apontada nos escritos, mas também haviam aquelas mulheres que habitavam o espaço para ter uma certa liberdade em suas ações com relação à sociedade patriarcal da época.

Ao analisar os inventários de 50 religiosas do Convento do Desterro entre os anos de 1717 e 1853, a historiadora Ana Amélia V. Nascimento (1994, p. 222), aponta que 21 destas religiosas possuíam livros devocionais. Com relação aos tipos de obras foram encontrados: Jogos de Breviário (32,37\%), Livrinhos Espirituais (44,60\%), Livros de Horas (1,44\%), Cadernos Velhos (2,16\%), Livros de Latim (5,04\%), Livros (13, 67\%) e cadernos de Ofício Divino $(0,72 \%)$. As religiosas que possuíam mais livros eram: Maria Madalena de Pazzi (óbito em 1781), com 20 livros espirituais e 04 tomos de breviários; Brites da Esperança (óbito em 1731), com 18 livros espirituais e cadernos "sem valor"; Mariana das Chagas (óbito

\footnotetext{
${ }^{8}$ CARTA pastoral ao Arcebispo eleito D. Fr. Manuel de Santa Ignez, dirigida às Religiosas do Convento de Santa Clara do Desterro da Cidade da Bahia, na qual se refere aos abusos e relaxações que ali se encontrara na sua visita e lhes dá instruções rigorosas para os coibir. Bahia, 9 de junho de 1764. Arquivo Histórico Ultramarino. Bahia - Eduardo de Castro e Almeida. Cx.35. Doc. 6556. [Grifos nossos]
} 
em 1750). A Sóror Maria Madalena de Pazzi esteve enclausurada por 36 anos e era filha de Francisco de Albuquerque Câmara, senhor de engenho em Penedo, Pernambuco. A Sóror Brites da Esperança permaneceu na instituição por 47 anos e era filha do negociante soteropolitano Francisco Correa Lima. Já a Sóror Mariana das Chagas também era filha de um negociante, João Pinto Brandão Magalhães e permaneceu por 30 anos na instituição, porém professou na religião com o véu branco (NASCIMENTO, 1994, p. 461). Este último caso torna-se uma demonstração importante do distanciamento da instituição com relação aos princípios clarianos. Se estava posto por meio da legislação que as irmãs conversas, aquelas que portavam véu branco, não participariam do Ofício Divino e, portanto, não necessitavam ter o domínio da leitura, como podemos compreender que uma religiosa desta categoria possuía tantos livros espirituais e cadernos "sem valor" no momento de sua morte? Provavelmente foi por causa dos embates e restrições com relação ao número de religiosas de véu preto no referido convento a partir da segunda metade do século XVIII e que acarretou esta diferenciação, uma vez que, independente do domínio da leitura e/ou da escrita, a única opção para a sua permanência enquanto freira poderia ser o porte do véu branco.

Dentre as obras que podemos caracterizar como "espirituais" ou "edificantes", destacam-se aquelas produzidas no interior do próprio Convento do Desterro, como as memorias conventuais e as vidas exemplares (biografias ou autobiografias). A escrita das memórias fazia parte do cotidiano dos conventos e demonstrava que as autoras "consultavam, aparentemente de forma criteriosa, documentos escritos dos arquivos das casas monásticas" (BELLINI, 2006/2007, p.210). Muitas memórias apresentam histórias de vida das freiras mais exemplares, o perfil sócio - econômico das recolhidas, as suas relações com os confessores, etc. Tais escritos demonstram o cuidado das memorialistas com as suas respectivas histórias institucionais.

Para além da utilização de documentos institucionais para a escrita das memórias é importante salientar a inserção da experiência da própria memorialista em seus escritos. Ao lembrar um episódio vivenciado no passado, o indivíduo reconstitui o que aconteceu, primeiro, a partir de uma massa ativa de reações ou experiências do passado organizadas, ou seja, a partir de uma estrutura já existente, como a linguagem, e de uma disposição que ele tem para lembrar e, segundo, a partir dos fragmentos que remanesceram da experiência vivenciada.

Na categoria "memórias" do Convento de Santa Clara do Desterro da Bahia destaca-se a obra escrita pela primeira escrivã, a eborense Sóror Maria de São Raimundo, que 
provavelmente utilizou de documentos escritos e da sua própria experiência para elaborar o texto. Não é possível datar precisamente a produção desta Memória, mas detecta-se que as últimas anotações da escrivã remetem ao ano de 1684. Por outro lado, é importante realçar que este documento faz parte da compilação realizada pelo Frei franciscano Antônio de Santa Maria Jaboatão, intitulada Novo Orbe Seráfico Brasílico ou crônica dos frades menores da província do Brasil, a qual teve a primeira publicação em 1761 e foi republicada pelo Instituto Histórico e Geográfico Brasileiro em 1858, versão utilizada neste trabalho (JABOATÃO,1858). Nas compilações do franciscano sobre o Convento do Desterro é possível encontrar a transcrição da Memória escrita por Sóror Maria de São Raimundo, caracterizada como um documento fundacional e que pode ser classificada como uma fonte dentro da própria memória dos franciscanos na América Portuguesa.

Em sua narrativa, a referida Sóror apresenta a longa viagem que as quatro fundadoras realizaram entre Évora e Salvador, as dificuldades da instalação e a chegada das primeiras noviças na casa. Segundo a autora, já havia uma profecia em sua casa de origem sobre o envio das fundadoras para uma "grande obra" no Brasil. Por conta desse caráter místico, várias irmãs concorreram para a empreitada que foi requerida pelo poder monárquico português:

Deixa-se isto conhecer no modo, com que no Mosteiro de nossa Madre Santa Clara da Cidade de Évora moveu a várias Religiosas o quererem passar ao Brasil a fundarem Convento, aonde as Donzelas daquele Estado se pudessem sacrificar a Deus, e sepultar-se em vida. Via-se o Estado do Brasil já muito povoado, achavam-se nele muitas Donzelas, que tocadas de luz superior desejavam dar de mão ao mundo, e servir a Deus; mas este fervor, e desejo de servir ao Senhor esfriava em umas o temor, e perigo dos mares, que para isso haviam de passar; e em outras a falta de cabedal para navegarem, e para se recolherem. Com que as menos vinham a ser as que a todo risco buscavam Mosteiro em Portugal. (Sóror Maria de São Raimundo. Memórias. Apud. JABOATÃO, 1858, p.650)

A escritora apresenta os anseios locais para a abertura do Convento do Desterro e a concorrência das religiosas do Convento de Santa Clara de Évora para a empreitada. Por outro lado, reafirma os princípios de que tomar o estado de religiosa seria uma forma de "sepultarse em vida", ao desejar o bloqueio de todos os contatos, necessidades e anseios do mundo exterior à clausura. Em 1678, a escrivã tornou-se também mestra das Noviças e então narrou em sua obra algumas características das primeiras 14 mulheres que ingressaram no convento baiano, as quais, segundo a autora, foram educadas para compreender os princípios da ordem propostos pela fundadora. Pela narrativa verifica-se que a preocupação com uma determinada 
educação religiosa fazia parte do cotidiano do convento desde a sua fundação e o aprendizado da leitura e do latim era necessário para a formação requerida para as clarissas. Além disso, destaca as origens familiares das primeiras recolhidas, todas pertencentes à elite baiana. (Sóror Maria de São Raimundo. Memórias. Apud. JABOATÃO, 1858, p.659)

A compilação realizada pelo Frei Jaboatão (1858) apresenta ainda a transcrição de algumas obras exemplares que foram escritas no interior ou no exterior do Convento do Desterro: Breve memória da Madre Soror Antônia do Paraiso, de autoria não identificada; a Vida e morte da serva do Senhor Sóror Maria da Soledade, escrita por Madre Margarida da Columna; e Vida e morte e boa fama que deixou de si a serva de Deos, Soror Vitoria da Encarnação escrita pelo Arcebispo da Bahia, D. Sebastião Monteiro da Vide, em $1720^{9}$. A análise inicial dessas trajetórias de vida aponta para o fato de que as três biografadas habitaram no mesmo período no Convento do Desterro, uma vez que Antônia do Paraíso entrou em 1690, com 15 anos de idade, e faleceu em 1717; Maria da Soledade ingressou com 19 anos em 1687 e faleceu em 1719; e Vitória da Encarnação ingressou em 1686 e morreu em 1717. A necessidade de pessoas distintas escreverem a biografia dessas três mulheres consideradas como "exemplares", com obras direcionadas para a leitura do grupo social que habitava o Desterro pode ter algumas correlações: primeiramente, os anseios de produzir obras que pudessem servir de exemplo local para as demais recolhidas; depois, a necessidade de praticar um determinado tipo de escrita e que era muito utilizado em outros espaços conventuais; por fim, a tentativa de regular e moralizar o cotidiano claustral.

As duas primeiras obras foram produzidas no interior do claustro e, possivelmente, seguiram os dois primeiros princípios apontados acima, porém a narrativa da vida de Irmã Vitória da Encarnação aproxima-se mais da terceira perspectiva, uma vez que foi produzida pelo arcebispo baiano, autoridade máxima da Igreja local. William Martins (2013) aponta que, ao se preocupar com a elaboração de uma escrita que apontava para um estilo de vida exemplar da Irmã Vitória e publicá-la em Roma, possivelmente havia uma preocupação do Arcebispo da Bahia para iniciar um processo de beatificação da mesma.

A análise da biografia da Irmã Vitória apresenta todos os dados importantes para estabelecer a exemplaridade para as demais religiosas. Verifica-se que ela tinha virtudes,

\footnotetext{
9 Também é possível consultar a publicação original desta última obra na Biblioteca Nacional de Portugal: D. Sebastião Monteiro da Vide. História de vida e morte de soror Victória da Encarnação. Religiosa professa no Convento de Santa Clara do Desterro da Cidade da Bahia. Para a Reverenda Abadessa e religiosas do mesmo Convento. Roma: Na Estamparia de Joam Francisco Chracas, 1720. microfilme FG 1349. BNP; e também está disponível on-line no site da Biblioteca Digital Luso Brasileira (http://bdlb.bn.br)
} 
guardava os votos e fazia penitencias. Na morte, passou a operar milagres, especialmente de curas. Ela era um exemplo para o alcance da perfeição tão almejada pelas religiosas da Casa. Ao finalizar a biografia, o autor expõe a sua intenção na escrita da obra, a moralização do Convento do Desterro por meio da exemplaridade da Madre Vitória:

Esta é a breve história da virtuosa, e exemplar vida de madre Vitoria da Encarnação, cuja saudosa memória esperamos que seja eficaz estimulo ás Reverendas Religiosas deste reformado e muito Religioso Convento de S. Clara da Bahia, para correrem a largos passos pela patente estrada da perfeição. (D. Sebastião Monteiro da Vide, Vida e morte. Apud. JABOATÃO, 1858, p. 702)

As obras exemplares seguiam uma estrutura quase que invariável, que pode ser detectada nas três vidas analisadas. Compreendia um percurso individual que começava com o nascimento e a indicação de um "chamamento" divino da criança para a vida religiosa. Inicialmente a menina não entendia este "chamamento" e passava por um período de negação, sempre incitada e tentada pelo Demônio. Quando entendia que a sua devoção futura só aconteceria ao ingressar em um convento, enfrentava as negativas de seus familiares, pois geralmente já estava encaminhada para um casamento laico. Quando finalmente ingressava no claustro, passava por diversos momentos de privações, tentações e invejas das demais recolhidas. Todo este caminho tornava-se necessário para conseguir alcançar a perfeição dentro do claustro, que só poderia acontecer por meio de suas orações, visões celestiais e as diversas intercessões entre os dois mundos, com uma aproximação direta com o "esposo". No momento de sua morte, sempre ocorria um sinal divino de sua pureza.

Para além de pensar a intencionalidade de uma obra escrita por um religioso e que fazia parte do poder local, como D. Sebastião Monteiro da Vide, torna-se necessário compreender quais eram as escritoras de vidas exemplares que habitavam o interior do referido Convento. Na obra do Frei Jaboatão (1858) só é possível identificar a escritora Madre Margarida da Columna (1662-1743), a qual também conviveu com as três biografadas e escreveu Vida e morte da serva do Senhor Sóror Maria da Soledade. Interessa aqui pensar a escritora, uma vez que é possível cruzar alguns dados sobre a sua inserção no cotidiano claustral. Foi batizada como Margarida da Costa Jardim na Vila de Cairú, próxima de Salvador e também pertencia à elite local, uma vez que era filha de Domingos Dias, indivíduo que exercia as funções de capitão, vereador e procurador do Senado da Câmara, instituição responsável por solicitar aos reis portugueses a abertura de um convento feminino em solo 
baiano (NASCIMENTO, 1994). Por conta da efetiva ação realizada pelo Senado da Câmara, os seus representantes alegavam ter prioridade para a entrada de suas filhas como educandas, noviças e futuras freiras na instituição ${ }^{10}$.

O Frei Jaboatão (1858, p.773) apresenta outras informações sobre a Sóror Margarida da Coluna, nome dado em homenagem à primeira Abadessa da instituição. Ela exerceu alguns cargos de destaque, uma vez que tornou-se Vigária do Coro $^{11}$ e, posteriormente, abadessa. A sua atuação neste último cargo influenciou o desenvolvimento de práticas de educação religiosa dentro do Convento, especialmente para as reclusas que não sabiam ler, por meio de investimentos da ampliação de leituras em voz alta e de orações para toda a comunidade: irmãs de véu preto, véu branco, noviças, educandas, recolhidas e servas.

Cuidou sempre e muito no aproveitamento, e bem espiritual não só daquelas pessoas, que tinha a seu cargo; mas em comum de todas, procurando por meio de Santos exercícios conduzir a todos ao caminho da Salvação. Todas as noites lia uma lição espiritual a que Ela chamava Lenda, e para que todas ouvissem o fazia na Capela do Senhor dos Passos, a qual acabada começava a rezar o terço da Senhora para o que compôs muitas jaculatórias, e obrigada a todas as Servas do Convento, sendo Prelada, para o que fossem rezar. (JABOATÃO, 1858, p.773)

Embora também demonstrasse atitudes para o caminho da perfeição, por meio do jejum, auto-flagelação com cilício e outros componentes, parece que a sua grande obra foi na divulgação do seu conhecimento, por meio da educação das noviças e de outras internas no Convento e assim não foi biografada interna ou externamente. Era conhecedora da língua latina e preocupava-se em difundí-la para as suas discipulas. "Nunca teve o tempo ocioso, por que ainda algum, que lhe restava dos seus espirituais exercicios, e outras ocupações, o gastava em ensinar a umas a lingua latina, que sabia muito bem e a outras a doutrina Cristã." (JABOATÃO, 1858, p.774)

\section{Conclusões}

Observa-se que havia uma intencionalidade dos autores em traçar um perfil das mulheres exemplares que habitavam o Convento de Santa Clara do Desterro em Salvador:

\footnotetext{
${ }^{10}$ CARTA dos oficiais da Câmara da Bahia para S. Magde, pedindo que se observe a provisão que se lhe passou para que as filhas prefiram às outras na entrada no convento de Santa Clara daquela cidade. Bahia, 30 de Junho de 1685. Arquivo Histórico Ultramarino. Bahia - Luisa da Fonseca. caixa 27, n. 3300-3301.
}

11 A Vigária de Côro era encarregada de controlar a qualidade da celebração do Ofício Divino (CONSTITUIÇÕES GERAES, 1693). 
todas deveriam viver modestamente, praticar atos de devoção e, além disso, deter um grau de letramento para participar do Ofício Divino e chegar mais próximo possível de Deus. Tais intenções também estavam apontadas em outras obras da época, escritas ou lidas na referida instituição. Para os conventos femininos, os representantes da Igreja Católica desejavam mulheres conhecedoras de determinadas obras, que detinham a leitura por meio do conhecimento da língua latina e talvez algumas até escrevessem no vernáculo, mas outras apenas rezavam ou escutavam a leitura das primeiras.As clarissas mais especiais eram aquelas mulheres que socialmente possuíam o conhecimento da leitura, ou da escrita, ou de ambos, e eram identificadas por meio da cor do véu que portavam na cabeça, muito embora esta prática não acontecesse com a maioria das habitantes do Convento do Desterro, uma vez que as intenções contidas nos discursos de busca da perfeição religiosa nem sempre eram almejadas pelas freiras.

\section{FONTES MANUSCRITAS}

CARTA do Arcebispo eleito D. Fr. Manuel de Santa Ignez para Francisco X. de Mendonça Furtado, na qual se refere à ordem regia que mandará suspender a admissão de noviças nos conventos das religiosas da Bahia, a respeito dos quais lhe dá diversas informações. Bahia, 30 de junho de 1764. Arquivo Histórico Ultramarino. Bahia- Eduardo de Castro e Almeida. Caixa 35. Doc. 6554- 6555.

CARTA dos oficiais da Câmara da Bahia para S. Magde, pedindo que se observe a provisão que se lhe passou para que as filhas prefiram às outras na entrada no convento de Santa Clara daquela cidade. Bahia, 30 de Junho de 1685. Arquivo Histórico Ultramarino. Bahia - Luisa da Fonseca. caixa 27, n. 3300-3301.

CARTA pastoral ao Arcebispo eleito D. Fr. Manuel de Santa Ignez, dirigida às Religiosas do Convento de Santa Clara do Desterro da Cidade da Bahia, na qual se refere aos abusos e relaxações que ali se encontrara na sua visita e lhes dá instruções rigorosas para os coibir. Bahia, 9 de junho de 1764. Arquivo Histórico Ultramarino. Bahia - Eduardo de Castro e Almeida. Cx.35. Doc. 6556.

REPRESENTAÇÃO da Abadessa do Convento de Santa Clara do Desterro, da Bahia, Sor Ana do Sacramento, e mais Religiosas à rainha [D. Maria I], solicitando a permissão de admissão de um maior número de religiosas no Convento, atendendo à vocação de muitas donzelas da mesma capitania. Bahia, 29 de outubro de 1779. Arquivo Histórico Ultramarino. Bahia-Avulsos. Cx. 178. Doc. 13318.

REQUERIMENTO de Francisca Maria ao rei [D. João V] solicitando concessão do lugar supranumerário do Convento de Santa Clara do Desterro da cidade da Bahia. 8 de fevereiro de 1747. Arquivo Histórico Ultramarino Bahia-Avulsos. Cx. 88. Doc. 7192 


\section{REFERÊNCIAS}

ALGRANTI, L. M. Livros de devoção, atos de censura. Ensaios de história do Livro e da leitura na América Portuguesa (1750-1821). São Paulo: HUCITEC, 2004

ANDRADE, M. F. P. C. In oboedientia sine proprio. A ordem de Santa Clara em Portugal (sécs. XIII-XIV). Tese de doutorado em História. Lisboa: Universidade Nova de Lisboa, 2011

ARAUJO, E. A arte da sedução: sexualidade feminina na colônia. In: DEL PRIORE, M. (Org.). História das mulheres no Brasil. São Paulo: Cia. das Letras, 1997. p. 45-70

BELLINI, L. Cultura escrita, oralidade e gênero em conventos portugueses (séculos XVII e XVIII). Tempo, v. 15, no. 29, p.212-233, 2010

BELLINI, L. Vida monástica e práticas da escrita entre mulheres em Portugal no Antigo Regime. Revista Campus Social. Universidade Lusófona de Humanidades e Tecnologia. n. 3/ 4, p. 209-218, 2006/2007.

BELO, F. Rellação da vida e morte da serva de Deos a venerável Madre Elenna da Crus por Sóror Maria do Céu. Lisboa: Quimera, 1993.

CARVALHO, J. A. F. Do recomendado ao lido. Direcção espiritual e prática de leitura entre franciscanas e clarissas em Portugal no século XVII. Via Spiritus. Porto, n. 4, p.7-56, 1997

CHARTIER, R. A história cultural: entre práticas e representações. Lisboa: Difel, 1990

CHARTIER, R. A ordem dos livros. Lisboa : Passagens, 1997

CONSTITUIÇÕES GERAES. Per a todas as freiras, e religiosas sogeitas à obediência da Ordem de N.P. S. Francisco, nesta família Cismontana. Lisboa: Na officina de Miguel Deslandes, impressor de Sua Magestade, 1693.

FARIA, F. L. (Coord.). Santa Clara e as clarissas em Portugal: VIII centenário do nascimento de Santa Clara. Lisboa: Instituto da Biblioteca Nacional e do Livro, 1994

FREI JOSEPH DE JESUS MARIA. Espelho de perfeytas religiosas. Exposição da segunda regra de Santa Clara. Lisboa: Officina de Joseph Lopes Ferreira, 1718.

GOMEZ, A. C. História de la cultura escrita. Ideas para el debate. Revista Brasileira de História da Educação. No. 5,p. 93-124, jan-jun. 2003.

JABOATÃO, A. S. M. Novo Orbe Seráfico Brasílico ou crônica dos frades menores da província do Brasil. V. II. Reimpressão do Instituto Histórico e Brasileiro. Rio de Janeiro: Typ. Brasiliense de Maximiano Gomes Ribeiro, 1858.

LAGE, A. C. P. Mulheres de véu preto: letramento religioso das irmãs clarissas na América Portuguesa. História. Questões e Debates. v.60, p.107 -131,2014 
MAGALHÃES, J. P. Tecendo nexos. História das instituições educativas. Bragança Paulista, SP: Editora Universitária São Francisco, 2004

MARTINS, W. S. Um espelho possível de santidade na Bahia colonial: madre Vitória da Encarnação (1661-1715). Revista Brasileira de História. São Paulo, ANPUH, v.33, no. 66, p.209-227, dez.2013.

NASCIMENTO, A. A. V. Patriarcado e Religião. As enclausuradas Clarissas do Convento do Desterro da Bahia. (1677-1890). Salvador: Conselho Estadual de Cultura, 1994

PEDROSO, J. C. C. Fontes Clarianas. Piracicaba, SP: Centro Franciscano de Espiritualidade, $4^{\text {a }}$. ed., 2004.

PEREIRA, J. A. C.(org.). Cadernos de espiritualidade franciscana. Braga, Pt: Editorial Franciscana, 2011

SARAMAGO, A. Convento de soror Mariana Alcoforado. Real mosteiro de Nossa Senhora da Conceição. Sintra, Portugal: Colares Editora, 1994

VASCONCELOS E SOUSA, B. (org.). Ordens religiosas em Portugal. Das origens a Trento. Lisboa: Livros Horizontes, 2005. 